\title{
Treatment of achalasia: Pneumatic dilation
}

\author{
G Vantrappen, MD, PhD, J Janssens, MD, PhD, P Rutgeerts, MD, PhD
}

ABSTRACT: Forceful dilation of the cardia is the treatment of choice for achalasia. This therapy can be carried out using a homemade system or using commercially available dilators. Pneumatic dilation yields $77 \%$ good or excellent results in patients with achalasia, while $8.7 \%$ have moderate improvement and $14.4 \%$ are not improved. The main complication is perforation, occurring in $2.5 \%$. Perforation can be treated medically with success. In the authors' series of now almost 1000 patients, only one died. Pneumatic dilation is a safe and effective procedure for the treatment of achalasia. Can J Gastroenterol 1990; 4(9):596-598

Key Words: Achalasia, Esophagus, Pneumatic dilation

\section{Le traitement de l'achalasie}

RESUME: La dilatation forcée du cardia est le traitement de choix de l'achalasie. Cette thérapie peut s'effectuer au moyen d'un instrument mis au point par le praticien ou d'un dilatateur commercialisé. La dilatation pneumatique donne $77 \%$ de résultats satisfaisants ou excellents, alors que $8,7 \%$ des patients s'améliorent modérément et que $14,4 \%$ d'entre eux ne réagissent pas. La perforation survient dans $2,5 \%$ des cas et constitue la complication majeure; elle se traite médicalement avec succès. Dans notre série de plus de 700 patients, un seul décès est survenu. La dilatation pneumatique est une procédure sûre et efficace utilisée dans le traitement de l'achalasie.
$\mathrm{T}$ HE CURRENT METHODS OF TREAT. ment of achalasia aim to improve the passage of food into the stomach by weakening the insufficiently relaxed sphincter (1-3). This can be achieved by stretching it forcefully (dilation) or by dividing the circular muscle (cardiomyotomy). Whatever treatment is chosen the sphincteric function should be preserved sufficiently to prevent reflux.
Department of Medicine, Division of Gastroenterology, University Hospital Gasthuisberg, Leuven, Belgium

Correspondence and reprints: Dr G Vantrappen, Professor of Medicine, Head, Department of Medicine, Division of Gastroenterology, University Hospital Gasthuisberg, Herestraat 49, 3000 Leuven, Belgium. Telephone (016) 214218

\section{PNEUMATIC DILATION}

Homemade system: To obtain good, long term results a forceful dilation of the sphincter is necessary. Several methods are currently available. For many years a pneumatic system with sippy-type dilator has been used(1). The dilator is assembled and thorough. ly tested before each dilation (Figurel).

To facilitate the introduction of the dilator a latex balloon is mounted around the nylon bag. The day before dilation the patient swallows a string (Mersilene number 1) weighted by a mercury filled bag. The string becomes anchored in the small bowel and acts as a guide for the dilator. If the esophagus is markedly widened and sigmoidshaped, the mercury filled bag may fail to pass into the stomach spontaneously. It may be possible to introduce it into the stomach with the help of a fibre. optic endoscope, or a Seldinger catheter may gently be passed under fluoroscopic control into the stomach and used instead of the Mersilene string as a guide for the dilator. Before introducing the balloon, a metal wire with an eye at the end is threaded over the string into the stomach, providing a rigid guide which ensures safe introduction of the dilator. If it is not possible to pass this rigid wire over the string, a 

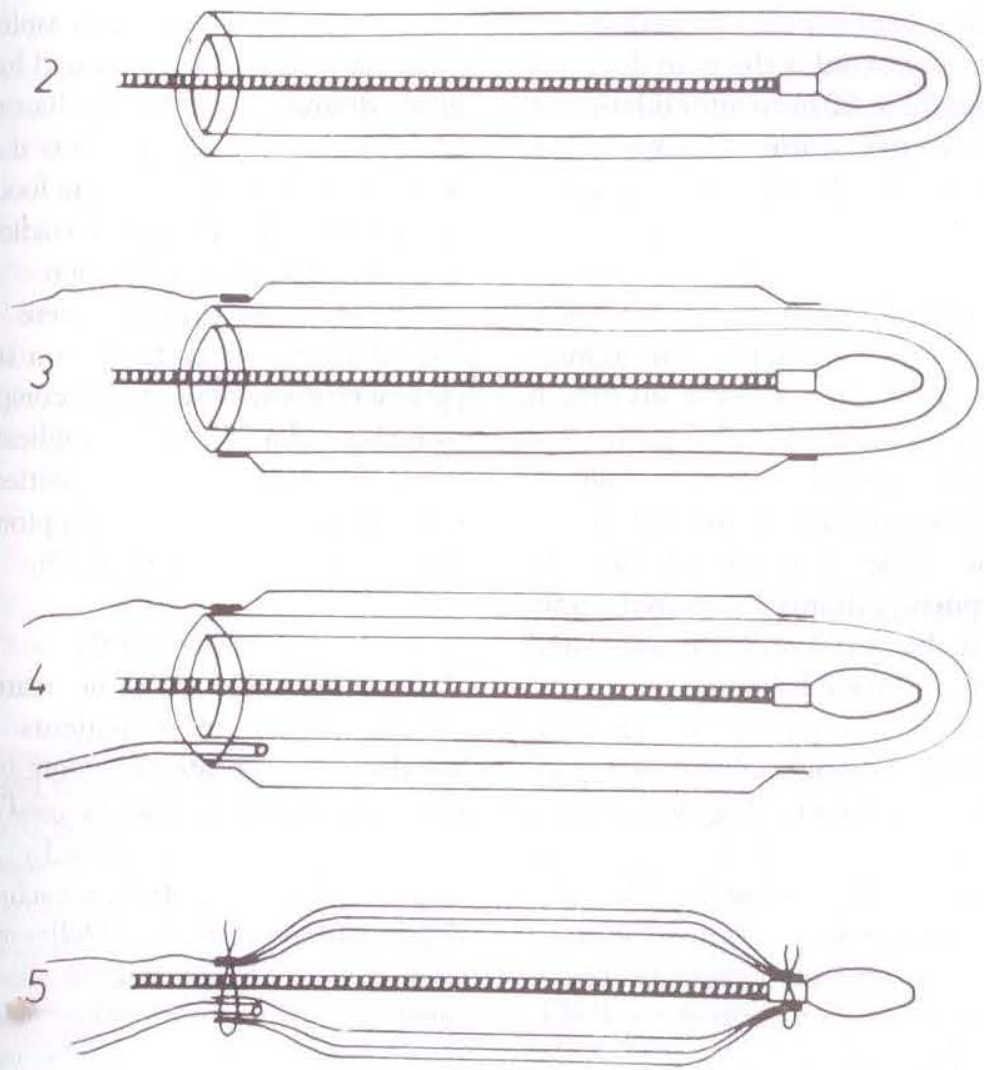

Figure 1) Mounting of the pneumatic dilator. Two latex balloons (condoms), one inside the other, surrounded by a nylon bag, are mounted on a metal spiral terminated by an olive bougie (1) (Mueller, Chicago). The nylon bags (2) have a length of $15 \mathrm{~cm}$ and a diameter of 3 to $5 \mathrm{~cm}$, depending upon the bag selected. At both ends the diameter of the bag tapers to about $1.5 \mathrm{~cm}$. A $50 \mathrm{~cm}$ nylon ribbon is sewn to the proximal end of the bag (3). On this ribbon a mark is made which indicates $40 \mathrm{~cm}$ from the middle of the bag. It also helps to ensure that the entire dilator, bag and spiral stay together when the dilator is pulled back at the end of the procedure. A polyvinyl cube with a noncompressible end (the tubing from an intravenous infusion set) is inserted between the balloons (4). When balloons and bags are ligated at both extremities (5), insufflation of air through the polyvinyl tube produces a cylinder, the diameter and shape of which are determined by the nylon bag. Pressure in the balloon can be measured by connecting the polyvinyl tube to a sphygmomanometer

more flexible wire should be used. If even such a flexible wire fails to enter deeply enough into the stomach, the dilator may be passed directly over the Mersilene string. The dilator is pushed down until the middle of the balloon reaches the level of the cardia (about $41 \mathrm{~cm}$ from the incisor teeth). The correct position of the balloon is always checked by fluoroscopy. In most cases an indentation on the left lateral aspect of the inflated balloon indicates the level of the diaphragm. The balloon is then insufflated to a pressure of 200 $\mathrm{mmHg}$ for the first minute, then to 300 $\mathrm{mmHg}$ for an additional minute. Initially a balloon with a diameter of $3 \mathrm{~cm}$ is used; at each subsequent session the calibre of the dilator is increased. Nylon bags with diameters of 3, 3.5, $3.8,4.2,4.5$ and exceptionally $5 \mathrm{~cm}$ should be available. Three to four dilations are performed in most patients until the criteria for adequate dilation are met. These include disappearance or substantial reduction of the pressure in the lower esophageal sphincter and, on fluoroscopy, easy emptying of the esophagus and widening of the previously narrow lower esophageal segment.

A liquid diet is given for a couple of days and the esophagus evacuated before the first dilation in order to prevent aspiration pneumonia. The dilation is performed with the patient in the upright position (standing or sitting) to avoid aspiration of secretions into the airways. If pain becomes severe, dilation is stopped. If the patient fails to cooperate sufficiently because of youth or mental disease, dilation is abandoned. Usually pain disappears or diminishes considerably within 2 mins after dilation ends. Analgesics are not given. A small amount of blood on the dilator as it is removed is normal and does not indicate a complication. Patients must refrain from drinking or eating for $2 \mathrm{~h}$ after dilation. If pain persists longer, perforation must be suspected. In that case, it is of the utmost importance that the patient not take anything by mouth and be given antibiotics as soon as possible. If the patient's condition is good $2 \mathrm{~h}$ after dilation, no other measures are necessary.

Commercially available systems: Microvasive achalasia dilators have 30 , 35 and $40 \mathrm{~mm}$ diameter polyethylene balloons of length $10 \mathrm{~cm}$ and mounted on a $100 \mathrm{~cm}$ long, 7 French shaft. Placement over a flexible guidewire is easy. This system is suitable for treatment of the majority of cases although the homemade system can better be adapted to a particular patient.

\section{RESULTS OF DILATION}

In the years 1957.85 the authors treated 700 patients by this method of pneumatic dilation. The immediate results were excellent. After the first dilation there was considerable improvement of dysphagia. By the end of treatment all patients stated that they were able to eat without distress. Regurgitation also disappeared completely. Attacks of substernal pain did not always disappear immediately; in some 
cases it took several weeks before relief was obtained, although crampy pain was less severe than before dilation. Most patients gained weight rapidly.

Late results could be evaluated for $93 \%$ of patients. They were subdivided into four groups according to the following criteria. Group 1 (excellent results) included patients who were completely free from symptoms. Group 2 (good results) comprised patients who experienced dysphagia or pain of short duration only occasionally: less than once a week there was hesitancy of food retrosternally, lasting from a few seconds to a couple of minutes, and disappearing on fluid intake; there was no weight loss or regurgitation. Group 3 (moderate results) patients experienced dysphagia at least once a week. The sensation of food sticking in the esophagus did not last longer than a few minutes and did not prevent the patient from finishing his or her meal. It was not accompanied by regurgitation or weight loss. These patients were markedly improved compared with the pretreatment situation. Group 4 (poor results) patients had frequent dysphagia, regurgitation or weight loss, or daily retrosternal pain.

At the time of evaluation, $77 \%$ of the patients had good or excellent results, $8.7 \%$ moderate results and $14.4 \%$ poor results; $93 \%$ of patients were significantly improved by treatment. The results of pneumatic dilation in patients with diffuse esophageal spasm were less satisfactory.

\section{COMPLICATIONS OF DILATION}

The major immediate complication of dilation is perforation of the esophagus at the cardia. Up to 1985 the authors had treated 700 patients and performed usually three or four pneumatic dilations per patient. Perforation occurred in $2.5 \%$ of the patients. A diagnosis of perforation was made whenever extravasation of contrast material could be demonstrated radiologically.

It is very important after each dilation to observe the patient carefully for possible complications. A perforation must be suspected if the pain does not diminish 30 to 60 mins after dilation or if it becomes worse. Crampy pains similar to attacks experienced spontaneously before treatment may be expected. However, if pain radiates to the back or left lower thorax, or if respiration becomes painful, perforation must be suspected. After a few hours breath sounds may diminish and there may be epigastric tenderness. A radiograph may show blurring of the left costophrenic angle or a pleural effusion. Hydropneumothorax occurred only once in this series and was associated with air in the mediastinum.

Whenever a patient experienced prolonged or abnormally severe pain after dilation, oral feeding was stopped and parenteral treatment with broad spectrum antibiotics started. The next day a radiographic examination with gastrografin was performed to check whether there was a perforation. If not, oral feeding was resumed as soon as the fever passed. If there was a perforation, broad spectrum antibiotics, analgesics and parenteral feeding were continued. Pleural aspiration or suction drainage were sometimes indicated. The majority of these patients improved considerably after about three days of conservative therapy. After that, food could be administered through a gastric tube, but this was not started immediately as it could cause vomiting. If surgical repair of the perforation was deemed necessary, it was best performed shortly after the accident. Residual abscesses of mediastinum of pleural cavity may require subsequent surgical drainage.

Perforation of the cardia, caused by pneumatic dilation, can usually be suc- cessfully treated conservatively. Most patients with proven perforation healed completely after parenteral alimentation and broad spectrum antibiotics for one or two weeks. Some. times a pleural effusion was aspirated Two patients had to be treated by sur. gical drainage of the mediastinum. Only one of the 700 patients died, a woman 83-years-old to whom food was given by mistake, in spite of a radiologir cally demonstrated perforation.

Other complications were prolonged pain, a peak fever or a sterile pleural effusion. The overall complication rate was $4.3 \%$. Late complications were rare after pneumatic dilation. In the authors' experience symptomatic reflux occurred in less than $1 \%$.

\section{CONCLUSION}

Pneumatic dilation is the treatment of choice for most patients with achalasia. It is a safe procedure in ex. perienced hands and can be used even when the esophagus is widened and tortuous or when the patient is cachectic. A previously unsuccessful Heller operation is not a contraindication to pneumatic dilation, if organic obstruc tion can be ruled out. The immediate and long term results compare favorab. ly with those of surgery, and stenosing reflux esophagitis is rare after pneumatic dilation.

\section{REFERENCES}

1. Vantrappen G, Hellemans J, Deloof W, Valembois P, Vandenbroucke J. Treat. ment of achalasia with pneumatic dilatations, Gut 1971;12:268-75.

2. Vantrappen G, Van Goidsenhoven G, Verbeke S, Van Den Berghe G, Vandenbroucke J. Manometric studies in achalasia of the cardia, before and after, pneumatic dilations.

Gastroenterology 1963;45:317-25.

3. Vantrappen G, Janssens J, Hellemans], Coremans G. Achalasia, diffuse esophageal spasm, and related motility disorders. Gastroenterology, 1979;76:450-7. 


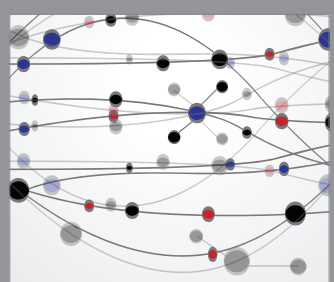

The Scientific World Journal
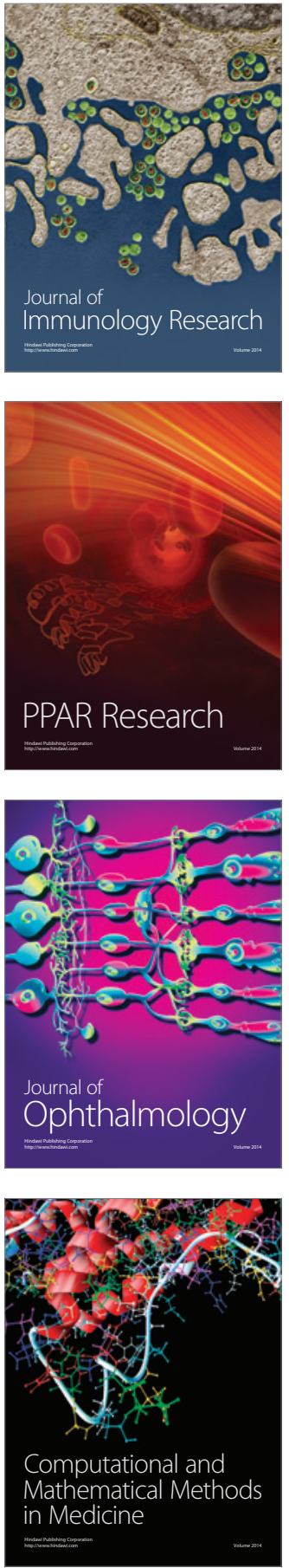

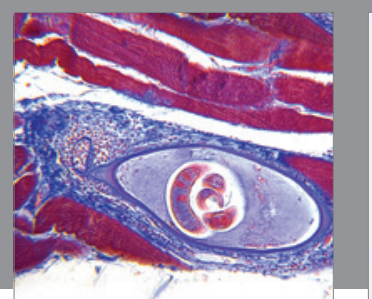

Gastroenterology Research and Practice

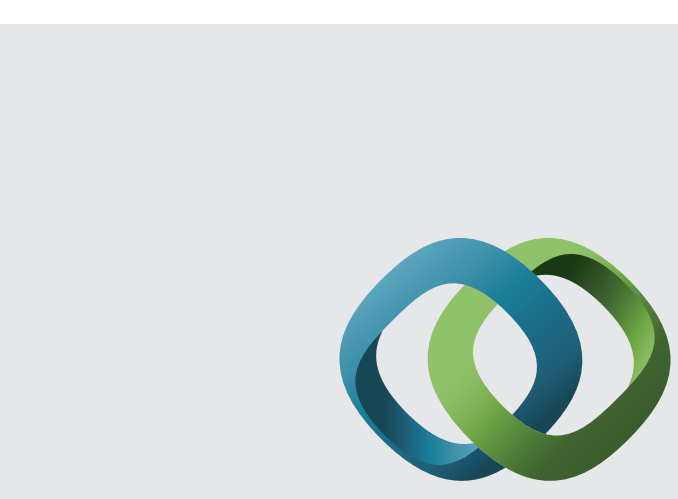

\section{Hindawi}

Submit your manuscripts at

http://www.hindawi.com
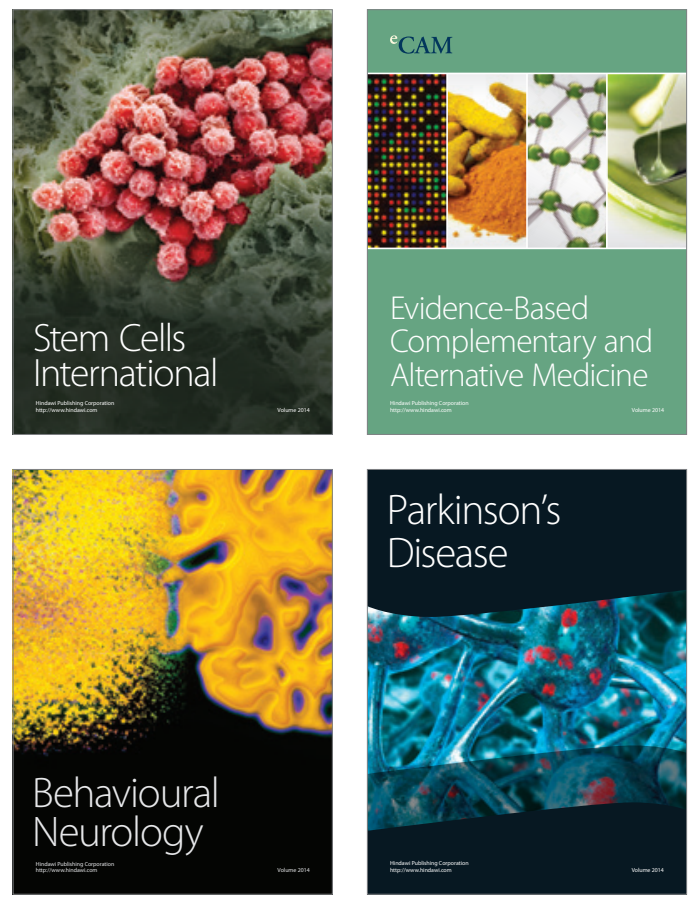
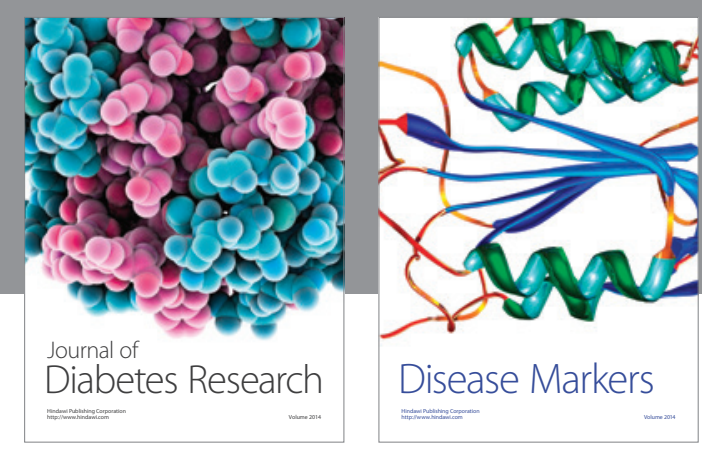

Disease Markers
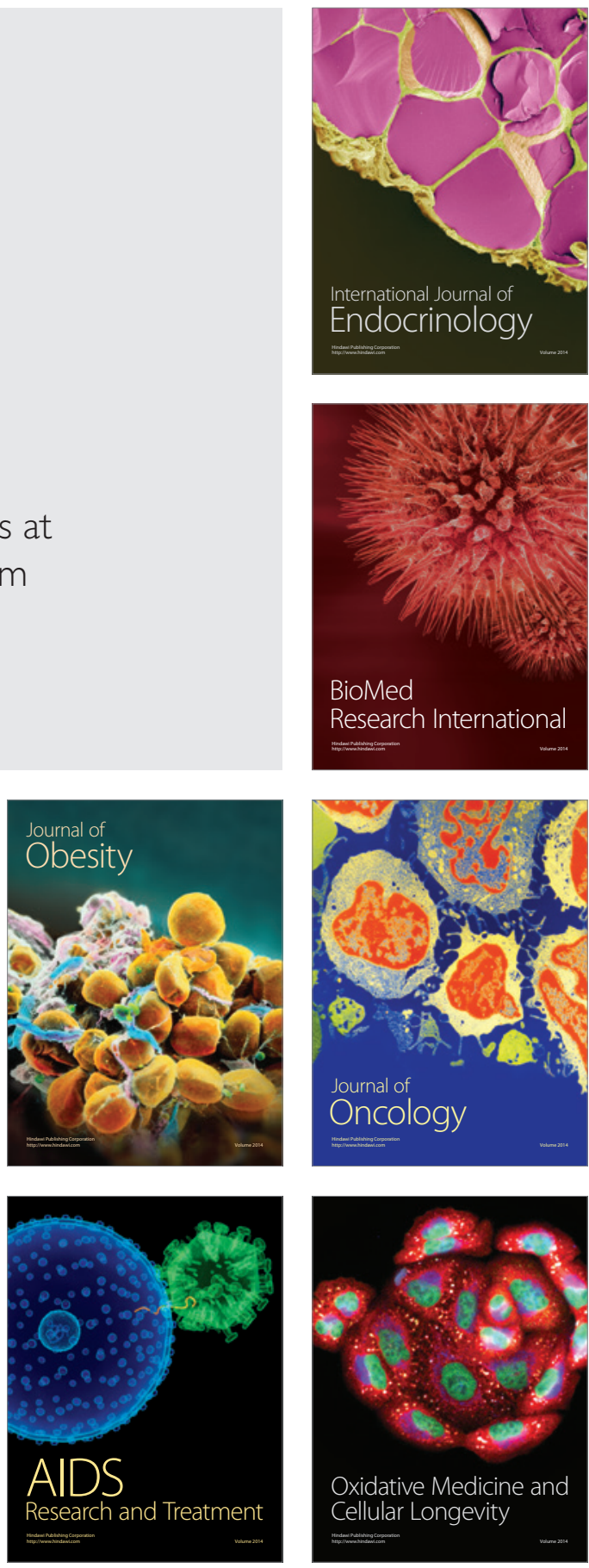